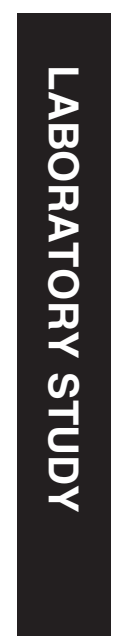

'Department of Ocular Pharmacology and Pharmacy, Dr Rajendra Prasad Centre for Ophthalmic Sciences, All India Institute of Medical Sciences,

Ansari Nagar, New Delhi, India

${ }^{2}$ Department of Biophysics, All India Institute of Medical Sciences, Ansari Nagar, New Delhi, India

${ }^{3}$ Department of Pharmacology, All India Institute of Medical Sciences, Ansari Nagar, New Delhi, India

${ }^{4}$ Indian Council for Medical Research, Ansari Nagar, New Delhi, India

${ }^{5}$ Dr Rajendra Prasad Centre for Ophthalmic Sciences, All India Institute of Medical Sciences, Ansari Nagar, New Delhi, India

Correspondence:

Dr T Velpandian, Department of Ocular Pharmacology \&

Pharmacy, Dr Rajendra Prasad Centre for Ophthalmic

Sciences, All India Institute of Medical Sciences, Ansari Nagar, New Delhi 110029, India. Tel: +9111 26593162;

Fax: + $911126593162 /$ 26588919

E-mail: tvelpandian@

hotmail.com

Received: 22 January 2013 Accepted in revised form: 24 May 2013

Published online: 12 July 2013

Presented at annual meeting of American Association of Pharmaceutical Scientists in 2010.

\section{Potential \\ pharmacokinetic role of organic cation transporters in modulating the transcorneal penetration of its substrates administered topically}

J Nirmal' ${ }^{1}$, SB Singh², NR Biswas ${ }^{3}$, V Thavaraj ${ }^{4}$, RV Azad ${ }^{5}$ and T Velpandian ${ }^{1}$

\begin{abstract}
Purpose We hypothesize organic cation transporters (OCT) may have a potential role in determining the pharmacokinetics and toxicity of organic cation drugs applied topically. Hence, in the present in vivo study, we attempted to evaluate the role of OCT in modulating the transport of its substrates after topical application.

Methods New Zealand albino rabbits of either sex were used. Transcorneal penetration of OCT substrates tetraethylammonium and metformin after single instillation was evaluated in the absence and presence of OCT blockers (quinidine and atropine). Aqueous humor (AH) samples were collected through paracentesis amounting to $70-100 \mu$ under topical anesthesia at various time intervals. The samples were subjected for estimation of both substrate as well as blocker concentrations using liquid chromatography mass spectrometry.
\end{abstract}

Results Topical pre-treatment $(30 \mathrm{~min}$ before substrate) of OCT blockers significantly decreased the transcorneal penetration of OCT substrates after single topical administration. The levels of blockers reaching $\mathrm{AH}$ in the presence of substrates were also modulated at $60 \mathrm{~min}$ after its administration as compared with its control. Conclusion OCT are functionally active in the uptake of their substrates from tear to AH. Therefore, OCT in the corneal epithelium may be positioned from apical to basolateral. When administering their substrates/blockers topically, both may be competing for OCT for their uptake across the cornea, thereby decreasing the corneal penetration. Hence OCT can have a potential pharmacokinetic role in modulating the ocular bioavailability of their substrates administered topically, which are used as ocular therapeutics.

Eye (2013) 27, 1196-1203; doi:10.1038/eye.2013.146; published online 12 July 2013

Keywords: organic cation transporters (OCT); transcorneal; pharmacokinetics; rabbits

Introduction

Topical administration of eye drops is a conventional and patient-compliant mode of drug administration to the eye. ${ }^{1}$ The majority of the topically applied drugs for treating anterior segment diseases utilize cornea as the main pathway to enter the eye from tear to aqueous humor $(\mathrm{AH}){ }^{2}$ Studies indicate that presence of a physiological protective mechanism like transporter proteins may be responsible for the uptake or altered penetration of drugs across the cornea. ${ }^{3-5}$ Most of the endogenous amines having a physiologically important role are organic cations (OC) and carry a positive charge, so they are unable to permeate across 
the cornea. Therefore, a specialized transport process has been reported to exist in the conjunctival and corneal epithelial cells involved in the regulation of the transport of various endogenous amines such as epinephrine, dopamine, histamine, and serotonin from tear fluid. ${ }^{6-8}$

Polyspecific organic cation transporters (OCT) mediate the facilitated transport of a wide variety of structurally diverse OC, including many drugs, toxins, and endogenous compounds. Few of the ophthalmic drugs that are transported by OCT are atropine, timolol, ofloxacin, and levofloxacin. ${ }^{9-12}$ In eye, these transporters are expressed in various ocular tissues like the cornea, iris, ciliary body, conjunctiva, and retina. ${ }^{13}$ Targeting these transporters will be a smart way of drug delivery aimed at optimal ocular bioavailability. ${ }^{1}$ The expression of OCT in the cornea and conjunctiva has been well documented. ${ }^{13}$ Many of the pharmacologically important drugs in ophthalmic practice are substrates of OCT, thereby their bioavailability is getting altered. ${ }^{4,14}$

Various studies in humans and animals showed the modulation in the ocular penetration of various OC. Additional administration of diclofenac sodium significantly increased the mean intraocular pressure (IOP) in patients undergoing latanoprost therapy. ${ }^{15}$ The effect of brimonidine in reducing the IOP was significantly reduced after oral administration of indomethacin. ${ }^{16}$ Even the possible drug-induced systemic toxicity was reduced when two OC, timolol, and phenylephrine were coadministered. ${ }^{17}$ Similarly, Lee et $_{a l}{ }^{18}$ showed that the coadministration of timolol with either pilocarpine or epinephrine significantly reduced the ocular absorption and thereby the concentration of timolol in the anterior segment tissues, possibly by its change during the precorneal clearance. All these findings have clinical importance; however, the reason for these significant findings of modulation in the ocular pharmacokinetics of OC is not clearly known.

We hypothesize OCT may have a potential role in determining the pharmacokinetics and toxicity of OC drugs applied topically. In previous studies, transport processes due to OCT were showed using ex vivo models in excised cornea, ${ }^{19}$ in vitro corneal cells, ${ }^{19}$ and excised conjunctiva $^{20}$ for understanding the functional importance of OCT. However, from the literature it was also evident that cell line studies did not reveal (due to minimal expression of transporters in the cell lines) the active functional role of OCT in transporting the administered eye drop. ${ }^{19}$ Studying the functional importance of OCT in vivo can reveal their role in the transport of organic cations across the cornea, when administered topically. It is well known that tetraethylammonium chloride (TEA) and metformin are cation substrates of OCT, and atropine and quinidine can inhibit the uptake of cation substrates. ${ }^{9,21-24}$ Hence, in the present study we used these substrates and inhibitors to understand the role of OCT in modulating the transport of their substrates across the cornea after topical application.

\section{Materials and methods}

\section{Drugs and chemicals}

TEA, quinidine sulfate and atropine sulfate were purchased from Sigma-Aldrich (St Louis, MO, USA). Metformin potassium chloride was a generous gift from Microlabs, Bangalore, India. Homatropine hydrobromide was purchased from Boehringer Ingelheim, Ingelheim, Germany. All other chemicals and solvents purchased from their respective commercial sources.

\section{Animals}

New Zealand albino rabbits of either sex weighing $1.5-2.0 \mathrm{~kg}$ were used in this study. Animals were handled in accordance with the guidelines of Association for Research in Vision and Ophthalmology statement for the use of Animals in Ophthalmic and Vision Research. All the experimental procedures were reviewed and approved by the standing Institutional Animal Ethics Committee of All India Institute of Medical Sciences (File No. 479/IAEC/09).

\section{Preparation and administration of drug formulations to rabbits}

Formulations were prepared as described previously in Nirmal et al. ${ }^{21}$ In brief, required concentrations of OCT substrates TEA $(7.85 \mathrm{mM})$ and metformin $(7.85 \mathrm{mM})$, and blockers quinidine $(6.13 \mathrm{mM})$ and atropine $(3.47 \mathrm{mM})$ were dissolved in phosphate-buffered saline and $\mathrm{pH}$ maintained at 7.4. The resulting solutions were filtered through a $0.22-\mu \mathrm{m}$ sterile Millipore filter (Millex GV filter, Millipore, Billerica, MA, USA) to achieve terminal sterilization. Fresh sterile solutions were prepared every time before the experiments. All formulations (substrate/ blocker) amounting to $20 \mu$ l were instilled topically to the rabbit's eyes using a calibrated micropipette and the eyes were closed for a minute after instillation. In blocker pre-treated animals quinidine or atropine was instilled $30 \mathrm{~min}$ prior to the commencement of substrate instillation.

\section{Transcorneal penetration of topical OCT blockers}

The animals were randomized into two groups (four eyes for each time point). The groups were quinidine 
(group 1) and atropine (group 2). In both the groups, the $\mathrm{AH}$ was collected at different time intervals $(15,30,60$, and $120 \mathrm{~min}$ ) and the $\mathrm{AH}$ kinetics of blockers were evaluated. For collecting the AH, the corneas were anesthetized with $4 \%$ lidocaine. AH was withdrawn with a 30-G sterile hypodermic needle via paracentesis amounting to $70-100 \mu \mathrm{l}$ and stored at $-80^{\circ} \mathrm{C}$ until further analysis by liquid chromatography mass spectrometry (LC-MS/MS).

\section{Transcorneal penetration of topical OCT substrates}

The AH kinetics of OCT substrates (TEA and metformin) in the absence and presence of blockers (quinidine and atropine) was studied using rabbits. Animals were randomized into eight groups (4 eyes for each time point): TEA (group 3), metformin (group 4), TEA with quinidine (group 5), TEA with atropine (group 6), metformin with quinidine (group 7), and metformin with atropine (group 8). In all groups, the $\mathrm{AH}$ was collected at different time intervals $(15,30,60$, and $120 \mathrm{~min}$ ) according to the procedure given above.

\section{LC-MS/MS analysis}

LC-MS/MS instrumentation for TEA, other substrates and blockers used in this study was used as described in our previous study. ${ }^{25}$ For all analytes electron spray ionization was used and the chromatographic eluents were subjected to ionization in the positive ion mode at 5500 V. TEA was quantified as described in Nirmal et al. ${ }^{25}$ The method used for the analysis of metformin was adopted from Mistri et $a l^{26}$ with slight modifications as described in our previous study. ${ }^{25,27,28}$ The LC conditions for metformin, quinidine, and atropine were followed as given. An isocratic mobile phase containing $80 \%$ acetonitrile with $0.1 \%$ formic acid and $20 \%$ aqueous $5 \mathrm{mM}$ ammonium acetate containing $0.1 \%$ formic acid was used. The mobile phase was $0.22 \mu \mathrm{m}$, filtered, degassed online, and pumped at the rate of $0.5 \mathrm{ml} / \mathrm{min}$. The samples were loaded into a 96-well tray and injected using an auto sampler and kept at $20^{\circ} \mathrm{C}$. Twenty microliters of the sample was subjected to quantification for 5 min run time.

Quantification of metformin was performed using the multiple reaction monitoring (MRM) mode, based on parent/product ion transitions 130/71. Compounddependent parameters such as declustering potential, entrance potential, collision energy and cell exit potential were set at $41,8,35$, and $5 \mathrm{~V}$, respectively. Nitrogen gas flow for collision-induced dissociation and dwell time were kept at 4 (arbitrary value) and $100 \mathrm{~ms}$, respectively.

The method used for the quantification of quinidine was adopted from Liu et al ${ }^{29}$ with minor modifications. ${ }^{27,30}$ The MRM transitions were 325.2/ 172.1 (transition 1) and 325.2/79.1 (transition 2). Compound-dependent parameters such as declustering potential, entrance potential, collision energy, and cell exit potential were set at 58,10,47, and $10 \mathrm{~V}$ for transition 1 , and at 57, 10, 61.64, and $5.5 \mathrm{~V}$ for transition 2 , respectively. Nitrogen gas flow for collision-induced dissociation and dwell time were kept at 3 (arbitrary value) and $100 \mathrm{~ms}$, respectively.

The method adopted from Chen et $a l^{31}$ with minor modifications ${ }^{27,30}$ was used for the quantification of atropine. The MRM transitions were 290.11/124.

Compound-dependent parameters such as declustering potential, entrance potential, collision energy, and cell exit potential were set at $79,4,35$, and $10 \mathrm{~V}$, respectively. Nitrogen gas flow for collision-induced dissociation and dwell time were kept at 3 (arbitrary value) and $100 \mathrm{~ms}$, respectively.

The source-dependent parameters of the mass spectrometer were gas 1 (30 psi); gas 2 (60 psi); curtain gas (10 psi); ion spray voltage $(5500 \mathrm{~V})$; and temperature $\left(350^{\circ} \mathrm{C}\right)$ for metformin, quinidine and atropine. The transitions for homatropine were 276.1/142. Homatropine was used as an internal standard (IS) for all the drugs, and the conditions were followed as described in Nirmal et al. ${ }^{25}$

\section{Standard and sample preparation}

The stock concentrations of TEA, metformin, quinidine, and atropine used were $7.84,7.85,6.13$, and $3.468 \mu \mathrm{mol} /$ $\mathrm{ml}$. The stock solution was diluted with $50 \%$ methanol containing $0.1 \%$ formic acid to reach the required concentrations ranging from low to high. The stock solution $(3.63 \mu \mathrm{mol} / \mathrm{ml})$ of IS was further diluted to reach $1.8 \mathrm{nmol} / \mathrm{ml}$ in the extraction solvent containing $70 \%$ acetonitrile with $0.1 \%$ formic acid. Twenty microliters of AH sample was extracted using $200 \mu \mathrm{l}$ of extraction solvent, vortexed for $1 \mathrm{~min}$, and subjected to centrifugation. The clear supernatant of $100 \mu \mathrm{l}$ was transferred to 96-well plates and subjected to quantification.

\section{Pharmacokinetics and statistical analysis}

The area under the curve (AUC) of $\mathrm{AH}$ concentration upto $2 \mathrm{~h}\left(\mathrm{AUC}_{0-2}\right)$ was calculated by using the linear trapezoidal rule using standard formulae. ${ }^{32}$

The results are represented as mean \pm SEM. Student's $t$-test (unpaired) was used to compare the significance between the control and blocker pre-treated groups using SigmaStat statistical software programme ver.2.0 (Jandel, San Jose, CA, USA). 


\section{Results}

Transcorneal penetration of OCT blockers in the absence of substrates

The transcorneal penetration shows the maximum concentration of quinidine and atropine reached at $30 \mathrm{~min}$ was $1.13 \pm 0.38$ and $0.54 \pm 0.06 \mathrm{nmol} / \mathrm{ml}$, respectively, after a single topical application (Figure 1). Based on this observation the blocker pre-treatment time has been fixed as 30 min before the substrate administration.

\section{Effect of OCT blockade in the transcorneal penetration of TEA}

TEA (referred to as control) was administered either alone or in the presence of quinidine or atropine (referred to as quinidine pre-treated or atropine pre-treated).

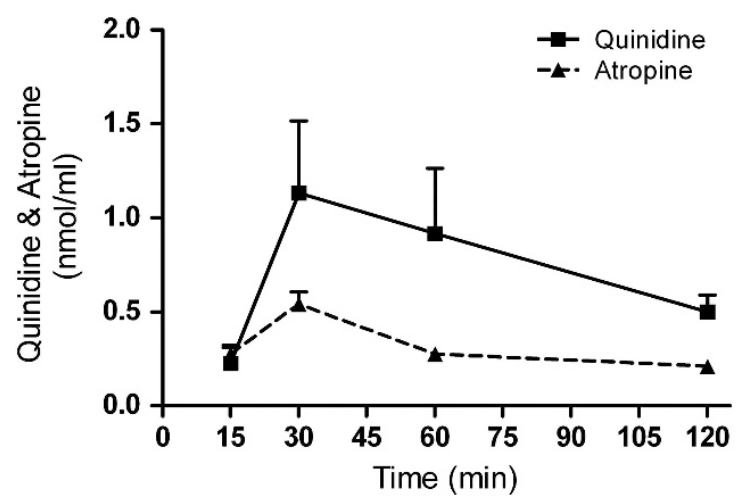

Figure 1 Transcorneal penetration of quinidine and atropine in the absence of substrate. Mean concentration-time profile of quinidine and atropine in the $\mathrm{AH}$ was measured after single topical administration in rabbit's eye. The values are shown as mean \pm SEM.

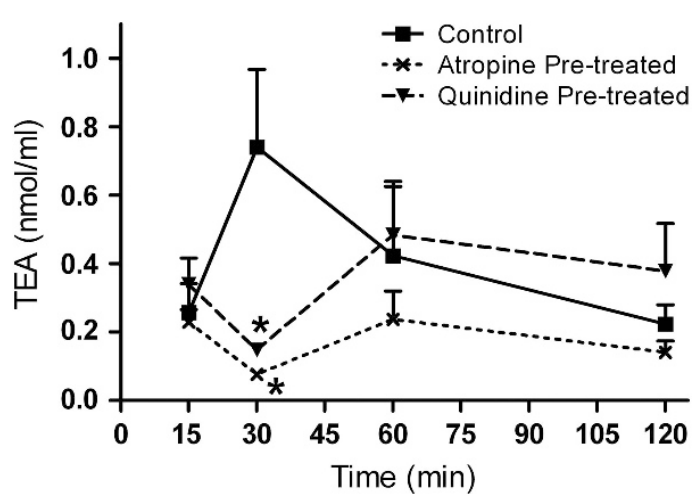

Figure 2 Transcorneal penetration of TEA in the absence and presence of blockers. Mean concentration-time profile of TEA in the $\mathrm{AH}$ was measured after single topical administration in rabbit's eye. Note: TEA alone (control); TEA in the quinidine or atropine pre-treatment group (quinidine or atropine pretreated). The values are shown as mean \pm SEM. ${ }^{*} P<0.05$.
AH levels of TEA in the control group reached its $T_{\max }$ at $30 \mathrm{~min}$ after the single topical instillation. The TEA levels in $\mathrm{AH}$ in the quinidine pre-treated group $(0.14 \pm 0.01 \mathrm{nmol} / \mathrm{ml})$ were significantly $(P<0.05)$ reduced when compared with the control group $(0.73 \pm 0.22 \mathrm{nmol} / \mathrm{ml})$ at $30 \mathrm{~min}$ (Figure 2$)$. The transcorneal penetration of TEA in the blocker pre-treated groups showed that the blocker was effective till $30 \mathrm{~min}$ after TEA instillation (Figure 2). Percentage penetration of the control and quinidine pre-treated groups was found to be $0.47 \%$ and $0.41 \%$, respectively. The AUCs of the control and quinidine pre-treated groups were 0.73 and $0.64 \mathrm{nmol} / \mathrm{ml} \cdot \mathrm{h}$, respectively. The $C_{\max }$ of TEA in the control group was $0.73 \pm 0.22 \mathrm{nmol} / \mathrm{ml}$. At the same time point, blocker pre-treatment decreased the TEA penetration to $0.14 \pm 0.016 \mathrm{nmol} / \mathrm{ml}$, which was found to be 5.2-fold less compared to control (Table 1). Atropine had a significant effect on the transcorneal penetration of TEA. The $C_{\max }$ of TEA in the control group $(0.73 \pm 0.22 \mathrm{nmol} / \mathrm{ml})$ was significantly $(P<0.05)$ decreased to $0.076 \pm 0.002 \mathrm{nmol} /$ $\mathrm{ml}$ at $30 \mathrm{~min}$ in the atropine pre-treated group (Figure 2). In case of percentage penetration, the atropine pre-treated group was 2.5-fold less than the control group. The AUC and $C_{\max }$ of TEA were decreased to 2.4- and 10.4-fold in the presence of atropine (Table 1).

\section{Fate of quinidine and atropine in the presence of TEA}

Quinidine/atropine (referred to as control) was administered either alone or in the presence of TEA (referred to as experimental). The estimation of quinidine levels in AH showed that the transcorneal penetration of quinidine was higher than that of TEA in the control and quinidine pre-treated groups. In the presence of substrate (TEA) penetration of blocker to AH decreased drastically (Figure 1a, Supplementary Data). Atropine levels reached $\mathrm{AH}$ in both the control and experimental groups (Figure 1b, Supplementary Data). However, atropine levels in both groups were less when compared with TEA (control) (Figures 2 and 1b, Supplementary Data).

\section{Effect of OCT blockade in the transcorneal penetration of metformin}

Metformin (referred to as control) was administered either alone or in the presence of quinidine or atropine (referred to as quinidine pre-treated or atropine pretreated). The maximum aqueous level of metformin $\left(C_{\max }\right)$ for the control group was attained at $30 \mathrm{~min}$, and was found to be $0.108 \pm 0.03 \mathrm{nmol} / \mathrm{ml}$. In the quinidine pre-treated group, the metformin levels were significantly decreased to $0.02 \pm 0.005 \mathrm{nmol} / \mathrm{ml}$ at $30 \mathrm{~min}$ $(P<0.05)$. It shows that there was a 5.4 -fold decrease in 
Table 1 The calculated pharmacokinetic parameters of TEA in AH after topical administration

\begin{tabular}{lccccr}
\hline Parameters & Control & $\begin{array}{c}\text { Quinidine } \\
\text { pre-treated }\end{array}$ & $\begin{array}{c}\text { Fold } \\
\text { (decrease) }\end{array}$ & $\begin{array}{c}\text { Atropine } \\
\text { pre-treated }\end{array}$ & $\begin{array}{c}\text { Fold } \\
\text { (decrease) }\end{array}$ \\
\hline Percentage penetration $(\%)$ & 0.47 & 0.41 & 1.2 & 0.19 & 2.5 \\
AUC $_{0-2}(\mathrm{nmol} / \mathrm{ml}$ ) & 0.73 & 0.64 & 1.5 & 0.30 & 2.4 \\
Concentration at $30 \mathrm{~min}(\mathrm{nmol} / \mathrm{ml})$ & 0.73 & 0.14 & 5.2 & 0.07 & 10.4 \\
\hline
\end{tabular}

Note: TEA (control); TEA in the quinidine or atropine topical pre-treatment group (quinidine or atropine pre-treated). The decrease in fold was calculated from control vs quinidine or atropine pre-treated.

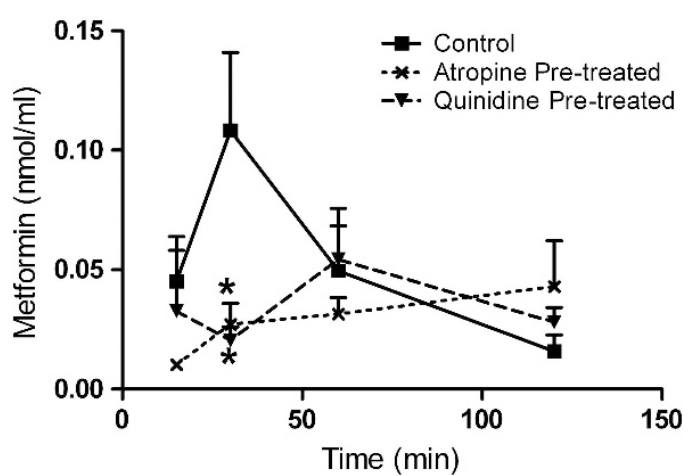

Figure 3 Transcorneal penetration of metformin in the absence and presence of blockers. Mean concentration-time profile of metformin in the $\mathrm{AH}$ was measured after single topical administration in rabbit's eye. Note: Metformin alone (control); metformin in the quinidine or atropine pre-treatment group (quinidine or atropine pre-treated). The values are shown as mean \pm SEM. ${ }^{*} P<0.05$.

the penetration of metformin in the quinidine pre-treated group compared with the control group. The above results imply that the blocker was effective till $30 \mathrm{~min}$ after metformin instillation (Figure 3 ). The percentage penetration of metformin in the quinidine pre-treated group was $0.042 \%$, whereas in the control group it was $0.058 \%$. This shows that the blocker pre-treated group was 1.6-fold less than the control group. The AUC of the control and quinidine pre-treated groups was 0.091 and $0.066 \mathrm{nmol} / \mathrm{ml} \cdot \mathrm{h}$, respectively (Table 2 ). The levels of metformin in the atropine pre-treated group were less at the initial time points and gradually increased at later time points. Metformin levels in the atropine pre-treated group, as shown in Figure 3, were significantly $(P<0.05)$ decreased as compared with the control at $30 \mathrm{~min}$. The aqueous concentration of metformin at $30 \mathrm{~min}$ was $0.027 \pm 0.008 \mathrm{nmol} / \mathrm{ml}$ in the atropine pre-treated group and was found to be four fold less than that in the control group. In case of percentage penetration, the blocker pre-treated group was 1.9-fold less than the control.

\section{Fate of quinidine and atropine in the presence of metformin}

Quinidine/atropine (referred to as control) was administered either alone or in presence of metformin (referred to as experimental). Aqueous quinidine level in the control was slightly less than that in the experimental group (Figure 2a, Supplementary Data). The levels of blocker reaching $\mathrm{AH}$ were higher when compared with the substrate (metformin). The levels of atropine in the control and experimental groups were higher than metformin levels, indicating higher aqueous penetration of the blocker than the substrate (Figure 2b,

Supplementary Data).

\section{Discussion}

Many of the clinically interesting ophthalmic drugs are OC, due to which their transport across the corneal epithelium heavily depends on transporter carriers. ${ }^{4}$ Despite the restriction offered by the corneal epithelium, transcorneal penetration is the major route of entry for drugs from tears to AH. ${ }^{5}$ Hence, cationic drugs may utilize some uptake transporters for their permeation across biological membranes. ${ }^{19,20,28}$ Presence of transporters like OCT in the conjunctival and corneal epithelial cells to reabsorb various endogenous amines in the tear fluid has been well recognized. ${ }^{6-8}$ Moreover, evidence from molecular biology studies from our laboratory and others showed the presence of various OCT in cornea. ${ }^{13,27,30}$ OCTN1 and OCTN2 were suggested to be present at the apical region of cornea. ${ }^{33}$ Drug absorption can be greatly enhanced by targeting endogenously expressed transport systems. ${ }^{34}$ Hence the objective of this study was to investigate the functional importance of OCT-mediated carrier system on in vivo corneal penetration using appropriate substrates and blockers as pharmacological tools. To achieve this, TEA $^{20,23,35-37}$ and metformin ${ }^{23,38-42}$ were used as OCT substrates. Quinidine $\mathrm{e}^{23,36,43-45}$ and atropine ${ }^{9,23}$ were used as OCT blockers. The substrates and blockers were quantified in AH using LC-MS/MS and their representative peaks were shown (Figure 3,

Supplementary Data). For the first time in this study we showed the functional importance of OCT in the cornea for transport of topically applied xenobiotics using an in vivo rabbit model.

The factors contributing to precorneal disappearance of topically administered drugs include drainage through the lacrimal fluid pathway, absorption through 
Table 2 The calculated pharmacokinetic parameters of metformin in AH after topical administration

\begin{tabular}{lccccc}
\hline Parameters & Control & $\begin{array}{c}\text { Quinidine } \\
\text { pre-treated }\end{array}$ & $\begin{array}{c}\text { Fold } \\
\text { (decrease) }\end{array}$ & $\begin{array}{c}\text { Atropine } \\
\text { pre-treated }\end{array}$ & $\begin{array}{c}\text { Fold } \\
\text { (decrease) }\end{array}$ \\
\hline Percentage penetration $(\%)$ & 0.058 & 0.042 & 1.6 & 0.036 & 1.9 \\
$\mathrm{AUC}_{0-2}(\mathrm{nmol} / \mathrm{ml}$ ) & 0.091 & 0.066 & 1.3 & 0.056 & 1.6 \\
Concentration at $30 \mathrm{~min}(\mathrm{nmol} / \mathrm{ml})$ & 0.108 & 0.020 & 5.4 & 0.027 & 4.0 \\
\hline
\end{tabular}

Note: Metformin (control); metformin in the quinidine or atropine topical pre-treatment group (quinidine or atropine pre-treated). The decrease in fold was calculated from control vs quinidine or atropine pre-treated.

the conjunctival pathway, corneal absorption, and nonspecific absorption in other precorneal tissues. Although the functional role of OCT is known to be active from apical to basolateral in the conjunctiva, ${ }^{20}$ the role of OCT in the cornea is not clear as of now. Some transport process does exist in the corneal epithelia and is known to reabsorb the cationic endogenous amines from the tear. A study conducted in our laboratory to evaluate the effect of OCT blockade on the tear kinetics of OCT substrates administered topically concluded that OCT are involved functionally in precorneal disposition of topically applied drugs. 27,30 The precorneal disposition route of xenobiotics and corneal uptake of endogenous amines probably utilize OCT to transport from tear to $\mathrm{AH}$ across the cornea. A similar observation has been found using timolol coadministration with either pilocarpine or epinephrine and showed significant reduction in ocular absorption of timolol possibly due to its alteration during precorneal clearance. But the possible role of OCT in cornea was not known at that time. ${ }^{18}$

Hence, investigating the transcorneal penetration of topically applied OCT substrates can reveal the role of OCT in the cornea. To understand the role of OCT in corneal penetration of its topically applied substrates, $\mathrm{AH}$ of the rabbits was sampled by paracentesis at various time intervals for the quantification of both substrate as well as their topically applied blockers. To reduce the volume-induced tear drainage, the applied volume was kept at a minimum of $20 \mu \mathrm{l}$ having either the substrate or the blocker. The dose was fixed based on the IC50 value of TEA, metformin, atropine, and quinidine for OCT interaction from the literature. ${ }^{23}$

To determine the blocker pre-treatment time, $T_{\max }$ of the blockers quinidine and atropine reaching $\mathrm{AH}$ after single topical administration was studied individually in controlled conditions. Therefore, the blocker pretreatment was chosen at $30 \mathrm{~min}$ before the administration of substrates to study the modulation of transcorneal penetration of substrates. Topically applied TEA showed a maximum aqueous concentration at $30 \mathrm{~min}$ after its instillation. In this experiment, quinidine (blocker) pretreatment significantly reduced the concentration of TEA at $30 \mathrm{~min}$ to the extent of 5.2 -fold. When atropine was used as the blocker, the concentration of TEA was reduced to an extent of 10.4-fold in the AH (Table 1).

Similar to TEA, metformin has also shown a maximum aqueous concentration $\left(C_{\max }\right)$ at a $T_{\max }$ of $30 \mathrm{~min}$. Blocker pre-treatment with quinidine and atropine showed 5.4- and 4-fold reduction in the aqueous concentration of metformin at the 30-min time point. The difference in the inhibitory effects of quinidine and atropine toward the uptake of TEA and metformin may be due to the difference in the contribution of individual OCT to the uptake of TEA and metformin. In the presence of TEA or metformin, blocker concentrations were generally found to be reduced as compared with their control. From the above observation it was understood that topical blocker pre-treatment significantly affected the uptake of OCT substrates from the precorneal area to the AH. Therefore, it was evident that OCT are present in the cornea from apical to basolateral, and may have a functional role in the uptake of their substrates across the cornea when applied topically as it has been reported in the conjunctiva. ${ }^{20}$

At equimolar concentration, TEA showed 7 times higher aqueous $C_{\max }$ compared to metformin in the control experiments. Quinidine and atropine both showed almost similar percentage of aqueous penetration in the control studies at $30 \mathrm{~min}$ post instillation. This shows that both of them were unlikely to have any difference in the available OCT isoform susceptibility in cornea. Further studies are needed to clarify the substrate specificity to the various isoforms of OCT. OCT may be having a vital role in the uptake of topically applied drugs having OCT susceptibility. When administering OCT substrates/blockers topically, both may be competing for OCT for their uptake across the cornea, thereby decreasing the corneal penetration. The altered levels of OCT blockers in the presence of OCT substrates as compared with their control levels further support the above finding (Figures 1 and 2, and Supplementary Data). The observation from the present study would be having therapeutic relevance when two OCT substrates/blockers are administered concomitantly in ocular topical drug therapy. This interaction might render low aqueous bioavailability of topically applied drugs, especially when alkaloids like atropine and their 
derivatives are extensively used along with other cationic drugs like anti-infectives, anti-glaucoma, antiinflammatory, and anti-histaminics as ocular medication.

To conclude, OCT in the cornea may be functionally active from tear fluid to AH. OCT can have a potential pharmacokinetic role in modulating the ocular bioavailability of their substrates administered topically, which are used as ocular therapeutics.

\section{Summary}

What was known before

- The gene expression evidence of OCT in the cornea.

What this study adds

- Functional importance of OCT in the cornea.

\section{Conflict of interest}

The authors declare no conflict of interest.

\section{Acknowledgements}

We thank CSIR for providing SRF to Dr J Nirmal and the All India Institute of Medical Sciences for providing the intramural grant (F.6-1/2010-Acad) for this research work.

\section{References}

1 Hughes PM, Olejnik O, Chang-Lin JE, Wilson CG. Topical and systemic drug delivery to the posterior segments. Adv Drug Deliv Rev 2005; 57(14): 2010-2032.

2 Dey S, Gunda S, Mitra AK. Pharmacokinetics of erythromycin in rabbit corneas after single-dose infusion: role of P-glycoprotein as a barrier to in vivo ocular drug absorption. J Pharmacol Exp Ther 2004; 311(1): 246-255.

3 Sasaki H, Yamamura K, Mukai T, Nishida K, Nakamura J, Nakashima $\mathrm{M}$ et al. Enhancement of ocular drug penetration. Crit Rev Ther Drug Carrier Syst 1999; 16(1): 85-146.

4 Mannermaa E, Vellonen KS, Urtti A. Drug transport in corneal epithelium and blood-retina barrier: emerging role of transporters in ocular pharmacokinetics. Adv Drug Deliv Rev 2006; 58(11): 1136-1163.

5 Urtti A. Challenges and obstacles of ocular pharmacokinetics and drug delivery. Adv Drug Deliv Rev 2006; 58(11): 1131-1135.

6 Van Haeringen NJ. Clinical biochemistry of tears. Surv Ophthalmol 1981; 26(2): 84-96.

7 Martin XD, Brennan MC. Dopamine and its metabolites in human tears. Eur J Ophthalmol 1993; 3(2): 83-88.

8 Martin XD, Brennan MC. Serotonin in human tears. Eur J Ophthalmol 1994; 4(3): 159-165.

9 Muller J, Lips KS, Metzner L, Neubert RH, Koepsell H, Brandsch M. Drug specificity and intestinal membrane localization of human organic cation transporters (OCT). Biochem Pharmacol 2005; 70(12): 1851-1860.
10 Foote EFaH CE. Effects of probenecid and cimetidine on renaldisposition of ofl oxacin in rats. Antimicrob Agents Chemother 1998; 42: 456-458.

11 Sakanaka K, Kawazu K, Nishida K, Nakamura J, Nakashima M, Nakamura T et al. Transport of timolol and tilisolol in rabbit corneal epithelium. Biol Pharm Bull 2006; 29(10): 2143-2147.

12 Mulgaonkar A, Venitz J, Grundemann D, Sweet DH. Human organic cation transporters 1 (SLC22A1), 2 (SLC22A2), and 3 (SLC22A3) as disposition pathways for fluoroquinolone antimicrobials. Antimicrob Agents Chemother 2013; 57: 2705-2711.

13 Zhang T, Xiang CD, Gale D, Carreiro S, Wu EY, Zhang EY. Drug transporter and cytochrome P450 mRNA expression in human ocular barriers: implications for ocular drug disposition. Drug Metab Dispos 2008; 36(7): 1300-1307.

14 Lee VH. Membrane transporters. Eur J Pharm Sci 2000; 11(Suppl 2): S41-S50.

15 Sorkhabi R, Alipanahi R, Eftakhari-Milani A, Ghojazadeh L. The influence of topical diclofenac sodium on the ocular hypotensive effect of latanoprost in glaucoma patients. J Glaucoma 2011; 20(4): 240-243.

16 Sponsel WE, Paris G, Trigo Y, Pena M, Weber A, Sanford K et al. Latanoprost and brimonidine: therapeutic and physiologic assessment before and after oral nonsteroidal anti-inflammatory therapy. Am J Ophthalmol 2002; 133(1): 11-18.

17 Jarvinen K, Urtti A. Cardiac effects of different eyedrop preparations of timolol in rabbits. Curr Eye Res 1992; 11(5): 469-473.

18 Lee VH, Luo AM, Li SY, Podder SK, Chang JS, Ohdo S et al. Pharmacokinetic basis for nonadditivity of intraocular pressure lowering in timolol combinations. Invest Ophthalmol Vis Sci 1991; 32(11): 2948-2957.

19 Xiang CD, Batugo M, Gale DC, Zhang T, Ye J, Li C et al. Characterization of human corneal epithelial cell model as a surrogate for corneal permeability assessment: metabolism and transport. Drug Metab Dispos 2009; 37(5): 992-998.

20 Ueda H, Horibe Y, Kim KJ, Lee VH. Functional characterization of organic cation drug transport in the pigmented rabbit conjunctiva. Invest Ophthalmol Vis Sci 2000; 41(3): 870-876.

21 Nirmal J, Velpandian T, Singh SB, Biswas NR, Azad R, Thavaraj $\mathrm{V}$ et al. Evaluation of the functional importance of organic cation transporters on the ocular disposition of its intravitreally injected substrate in rabbits. Curr Eye Res 2012; 37(12): 1127-1135.

22 Masago M, Takaai M, Sakata J, Horie A, Ito T, Ishida K et al. Membrane transport mechanisms of quinidine and procainamide in renal LLC-PK1 and intestinal LS180 cells. Biol Pharma Bull 2010; 33(8): 1407-1412.

23 Koepsell H, Lips K, Volk C. Polyspecific organic cation transporters: structure, function, physiological roles, and biopharmaceutical implications. Pharm Res 2007; 24(7): 1227-1251.

24 Horie A, Sakata J, Nishimura M, Ishida K, Taguchi M, Hashimoto Y. Mechanisms for membrane transport of metformin in human intestinal epithelial Caco-2 cells. Biopharm Drug Dispos 2011; 32(5): 253-260.

25 Nirmal J, Velpandian T, Singh SB, Biswas NR, Thavaraj V Azad $\mathrm{R}$ et al. Development and validation of a highly sensitive LC-MS/MS method for organic cation transporter (OCT) substrate tetraethylammonium (TEA) in rabbits. 
J Chromatogr B Analyt Technol Biomed Life Sci 2011; 879(9-10): 585-590.

26 Mistri HN, Jangid AG, Shrivastav PS. Liquid chromatography tandem mass spectrometry method for simultaneous determination of antidiabetic drugs metformin and glyburide in human plasma. J Pharm Biomed Anal 2007; 45(1): 97-106.

27 Velpandian T, Nirmal J, Sirohiwal A, Singh SB, Vasantha T, Azad RV. Evaluation of the Modulation of Organic Cation Transporter (OCT) in the Tear Disposition of its Substrates in Rabbits. Assoc Res Vis Ophthalmol USA 2012, pp 5333/A5358.

28 Nirmal J, Velpandian T, Singh SB, Ranjan Biswas N, Azad R, Thavaraj V et al. Evaluation of the functional importance of organic cation transporters on the ocular disposition of its intravitreally injected substrate in rabbits. Curr Eye Res 2012; 37: 1127-1135.

29 Liu X, Van Natta K, Yeo H, Vilenski O, Weller PE, Worboys PD et al. Unbound drug concentration in brain homogenate and cerebral spinal fluid at steady state as a surrogate for unbound concentration in brain interstitial fluid. Drug Metab Dispos 2009; 37(4): 787-793.

30 Nirmal J, Velpandian T, Biswas NR, Azad RV, Vasantha T, Bhatnagar A, Ghose S. Evaluation of the relevance of OCT blockade on the transcorneal kinetics of topically applied substrates using rabbits. FIP 2010 World Congress in Association with AAPS, New Orleans, USA 2010, SA8208/T3427.

31 Chen H, Chen Y, Du P, Han F, Wang H, Zhang H. Sensitive and specific liquid chromatographic-tandem mass spectrometric assay for atropine and its eleven metabolites in rat urine. J Pharm Biomed Anal 2006; 40(1): 142-150.

32 Katragadda S, Talluri RS, Mitra AK. Simultaneous modulation of transport and metabolism of acyclovir prodrugs across rabbit cornea: An approach involving enzyme inhibitors. Int J Pharm 2006; 320(1-2): 104-113.

33 Garrett Q, Xu S, Simmons PA, Vehige J, Flanagan JL, Willcox MD. Expression and localization of carnitine/organic cation transporter OCTN1 and OCTN2 in ocular epithelium. Invest Ophthalmol Vis Sci 2008; 49(11): 4844-4849.

34 Steffansen B, Nielsen CU, Brodin B, Eriksson AH, Andersen R, Frokjaer S. Intestinal solute carriers: an overview of trends and strategies for improving oral drug absorption. Eur J Pharm Sci 2004; 21(1): 3-16.
35 Tamai I, Nakanishi T, Kobayashi D, China K, Kosugi Y, Nezu J et al. Involvement of OCTN1 (SLC22A4) in pH-dependent transport of organic cations. Mol Pharm 2004; 1(1): 57-66.

36 Zhang N, Kannan R, Okamoto CT, Ryan SJ, Lee VH, Hinton DR. Characterization of brimonidine transport in retinal pigment epithelium. Invest Ophthalmol Vis Sci 2006; 47(1): 287-294.

37 Franke RM, Kosloske AM, Lancaster CS, Filipski KK, $\mathrm{Hu} \mathrm{C}$, Zolk O et al. Influence of Oct1/Oct2-deficiency on cisplatin-induced changes in urinary $\mathrm{N}$-acetyl-beta-Dglucosaminidase. Clin Cancer Res 2010; 16(16): 4198-4206.

38 Dresser MJ, Gray AT, Giacomini KM. Kinetic and selectivity differences between rodent, rabbit, and human organic cation transporters (OCT1). J Pharmacol Exp Ther 2000; 292(3): 1146-1152.

39 Kimura N, Masuda S, Tanihara Y, Ueo H, Okuda M, Katsura $\mathrm{T}$ et al. Metformin is a superior substrate for renal organic cation transporter OCT2 rather than hepatic OCT1. Drug Metab Pharmacokinet 2005; 20(5): 379-386.

40 Choi MK, Song IS. Organic cation transporters and their pharmacokinetic and pharmacodynamic consequences. Drug Metab Pharmacokinet 2008; 23(4): 243-253.

41 Takane H, Shikata E, Otsubo K, Higuchi S, Ieiri I. Polymorphism in human organic cation transporters and metformin action. Pharmacogenomics 2008; 9(4): 415-422.

42 Chen L, Pawlikowski B, Schlessinger A, More SS, Stryke D, Johns SJ et al. Role of organic cation transporter 3 (SLC22A3) and its missense variants in the pharmacologic action of metformin. Pharmacogenet Genomics 2010; 20(11): 687-699.

43 Yabuuchi H, Tamai I, Nezu J, Sakamoto K, Oku A, Shimane $\mathrm{M}$ et al. Novel membrane transporter OCTN1 mediates multispecific, bidirectional, and $\mathrm{pH}$-dependent transport of organic cations. J Pharmacol Exp Ther 1999; 289(2): 768-773.

44 Kwok B, Yamauchi A, Rajesan R, Chan L, Dhillon U, Gao W et al. Carnitine/xenobiotics transporters in the human mammary gland epithelia, MCF12A. Am J Physiol Regul Integr Comp Physiol 2006; 290(3): R793-R802.

45 Umehara KI, Iwatsubo T, Noguchi K, Usui T, Kamimura H. Effect of cationic drugs on the transporting activity of human and rat OCT/Oct 1-3 in vitro and implications for drug-drug interactions. Xenobiotica 2008; 38(9): 1203-1218.

Supplementary Information accompanies this paper on Eye website (http://www.nature.com/eye) 